Capítulo 7

\title{
A supressão da voz feminina nos estudos comunicativo- midiāticos da América Latina. A ideia introdutória de 'mães' fundadoras do Pensamento Comunicacional'
}

DOI: https://doi.org/10.16921/ciespal.23.27

Maria Cristina Gobbi

Bolsista de produtividade do CNPq, Professora Livre docente da Universidade Estadual Paulista Júlio de Mesquita Filho (UNESP).

\section{Breve cenário e alguns de seus contextos}

Com uma cultura diversificada, uma geografia variada e um extenso território, a América Latina reúne 20 países com histórias que "corrieron paralelas y estuvieron unidas por semejanzas, pero también estuvieron marcadas por diferencias políticas, sociales e culturales" (Cano \& Barrancos, 2006, p. 547).

Neste contexto, o surgimento de espaços de reflexão e de pesquisa vem ao encontro dos processos de institucionalização que se desenvolveram em toda a região. Como afiança Corner (2019, p. 1), o "exame de como os programas de ensino e a atividade de pesquisa contribuíram para institucionalizar a área com uma identidade acadêmica discreta, embora muito debatida", também reforça o argumento. Estes estudos têm instigado a comunidade acadêmica para continuidade das investigações,

1 Integra o projeto "Do silenciamento à palavra: a presença da mulher nos estudos em comunicação na América Latina e a Agenda 2030", que conta com bolsa de apoio a pesquisa. Processo 2019/26715-2 da Fundação de Amparo à Pesquisa do Estado de São Paulo (Fapesp). 
buscando romper com a 'persistência da teoria negada', denunciada por Jesús Martin-Barbero, na década de 1982. (Fuentes Navarro, 2019)

No cenário da América Latina é possível afirmar, por um lado, que "las bases del desarrollo en el campo académico de la comunicación deviene del subcampo de la reproducción de la comunicación; es dicir, de las experiencias relativas al processo de enseñanza" (Léon Duarte, 2012, p. 237)2, em especial entre os anos de 1934-1935, com os movimentos de criação das primeiras escolas de comunicação. Por outro, somente a partir dos anos 1960 atuações institucionalizadas foram desenvolvidas e documentadas, tendo como marco pioneiro a criação do Centro Internacional de Estudios Superiores de Periodismo para América Latina (Ciespal). O impacto da presença do Centro para a região e para os estudos em comunicação estimulou e favoreceu a criação de diversos espaços de investigação, ampliando e desenvolvendo outra fisionomia para o campo comunicativo na busca de uma 'identidade comunicativa' própria para a região.

Assim, os estudos que tratam sobre a legitimação do campo da comunicação no continente, notadamente na perspectiva histórica, têm seu reconhecimento na própria região, quando da criação de instituições de ensino e de centros de investigações nacionais e internacionais, como Ciespal $^{3}$, em Quito, no Equador, em 1959; o Instituto de Ciências da Informação (Icinform), no Brasil, em 1963, na Universidade Católica de Pernambuco; o Centro de Estudios de la Realidad Nacional (Ceren), criado entre os anos de 1967 e 1969 na Universidad Católica de Santiago do Chile;

2 A afirmação está relacionada com criação, em 1934, na cidade de Buenos Aires, Argentina, na Universidad Nacional de La Plata (que teve seu início em abril de 1897), do primeiro curso de jornalismo. E, em seguida, no ano de 1935, quando teve início a primeira escola de jornalismo na América Latina. León Duarte (2010b) afirma que foram 131 estudantes inscritos nessa primeira investida.

3 Pouco antes da criação do Ciespal o Instituto Latinoamericano de la Comunicación Educativa (Ilce) já existia, criado em 1956, resultado de uma parceira entre a Unesco e o governo do México. Sua perspectiva principal era a de contribuir para a melhoria da educação na região através da utilização de meios e recursos audiovisuais, projetos educativos e sociais, ampliando o acesso a educação para a população. Denominado na época como Instituto Latinoamericano de la Cinematografía Educativa (ILCE), sua sede inicial foi na cidade do México. No final da década de 1960 amplia seu foco de ação a partir dos recursos tecnológicos disponíveis para "modernizar e satisfazer as carências educativas da América Latina" (Ilce, 2021). Do mesmo modo, altera sua denominação para Instituto Latinoamericano de la Comunicación Educativa, mantendo a sigla Ilce. 
o Consejo Nacional para la Enseñanza y la Investigación de las Ciencias de la Comunicación (Coneicc), criado em 1976 no México; a Sociedade Brasileira de Estudos Interdisciplinares da Comunicação (Intercom), de 1977 no Brasil; Asociación Latinoamericana de Investigadores de la Comunicación (Alaic), criada em 1978 e reconstruída em 1989; Associação Mexicana de Investigadores da Comunicação (Amic), criada em 1979, a Federação Latino-Americana de Faculdades de Comunicação Social (Felafacs), fundada na Colômbia em 1981; a Asociación Boliviana de Investigadores de la Comunicación (ABOIC), La Paz, em 1981, entre outras.

Neste mesmo período, a criação de publicações acadêmico-científicas de "vocação explicitamente latino-americana", como a Chasqui, no Equador (editada pelo Ciespal desde 1972); Comunicación y Cultura, publicada no Chile, Argentina e México (entre os anos de 1973 a 1985); a Revista da Alaic, que teve início nos anos de 1980 e Diálogos de la Comunicación, publicada pela Felafacs a partir de 1987, balizam e divulgam esta produção comunicativa. Também, o desenvolvimento de estudos historiográficos, em especial as compilações realizadas pela Alaic, que reuniu produções comunicativas (tanto teóricas, quanto práticas) da Argentina, Bolívia, Brasil, Chile, Colômbia, México, Peru e que objetivaram 'sistematizações documentais' da produção em comunicação na região ${ }^{4}$. Soma-se ao grupo, o ensaio 'Memória do campo acadêmico da comunicação: estado da arte do conhecimento empírico de natureza historiográfica', escrito por José Marques de Melo e publicado no livro do Congresso 2011 da Intercom ${ }^{5}$, que traz um inventário das incursões recentes sobre o tema. Entre outros estudos.

Assim, as evidências empíricas corroboram a produção comunicativa latino-americana, especialmente, a partir de duas frentes: na institucionalização dos estudos na região e no crescimento exponencial desta produção, incluindo contextos internacionais.

4 Chamado de projeto "ALAIC/CIID - Bibliografias básicas de Investigação em Comunicação e Cultura na América Latina", foi concebido para contemplar 5 países inicialmente: Argentina, Brasil, Chile, Colômbia e Peru e foi financiado pelo Centro Internacional de Investigaciones para el Desarrollo (CIID). (Gobbi, 2008, p. 117)

5 O tema do evento foi "Quem tem medo da pesquisa empírica?". 
Embora os estudos comunicativos na América Latina possam ser caracterizados pela ampliação dos espaços de formação, que favoreceu o ingresso da mulher na educação superior, especialmente a partir do século XIX ${ }^{6}$, evidencia-se a falta de atenção à produção realizada por elas, deixando parte considerável desaparecida. A consequência desse fato é que esse processo vem sistematicamente silenciando e escamoteando outras formas de conhecer, em particular aquelas produzidas em contextos e por sujeitos do conhecimento que não integram as estruturas de poder hegemônicas, reproduzindo o 'imaginário dominante', muito presente nos discursos coloniais, como bem afirma Resende (2021).

Traçado esse breve panorama inicial, na perspectiva de trazer as primeiras reflexões sobre a concepção de "mães fundadoras" ${ }^{\text {" }}$ do Pensamento Comunicacional Latino-Americano (PCLA), em contra-ponto a ideia dos "país fundadores", definimos como ponto de partida o espaço

6 Embora o exercício profissional ainda ocorra, em muitos casos, em uma posição de menor prestígio se comparada com os colegas do sexo masculino.

7 O termo 'mães fundadoras' se refere a perspectiva de pioneiras nos estudos comunicativos na América Latina. A concepção de pioneirismo teve como ponto de partida o estudo da divisão geracional (desbravadores, precursores, pioneiros, inovadores e renovadores) sobre os estudos Latino-Americanos em Comunicação, propostos por José Marques de Melo, contido no trabalho "Conhecer-produzir-transformar: paradigmas da Escola Latino-Americana de Comunicação", apresentado na abertura do VI Colóquio Brasil-França de Ciências da Comunicação, Universidade de Poitiers, França, 8 de Janeiro de 2001, tendo como ponto inicial as pesquisas realizadas no período de 1960 e de 1970.

8 José Marques de Melo (2001) definiu em seus vários estudos o grupo de pioneiros, integrado por representantes de diversos país da região. São eles: Eliseo Verón e Carlos Fayt (Argentina); Luis Ramiro Beltrán (Bolívia); Danton Jobim, Décio Pignatari e Luiz Beltrão (Brasil); Jorge Fernández e Ramiro Samaniego (Euqador); Henrique Gonzáles Casanova (México); Juan Díaz Bordenave (Paraguai); Antonio Pasquali, Jesús Marcano Rosas, Eleazar Díaz Rangel, Eduardo Santoro, Héctor Mujica (Venezuela); Roque Faraone e Mario Kaplún (Uruguai). A partir dessa sistematização muitos estudos foram realizados na região e alguns nomes incorporados a esse grupo, tal como o de Armand Matterlart, em especial no período que ele esteve no Chile. A única pesquisadora do grupo é Marta Colomina de Rivera (Venezuela). A história dos fundadores tem sido adotada em grande parte dos livros e textos que traçam a evolução do pensamento comunicacional. Embora o cenário escolhido para esse texto seja o da América Latina, é fundamental mencionar quatro nomes representativos dos primeiros aportes sobre os estudos de comunicação, em "cujas pesquisas emergem a partir da primeira metade do século passado, chamados de forefathers (pais fundadores) por Wilbur Schramm: o cientista político Harold Dwight Lasswell (19021978), o sociólogo Paul Felix Lazarsfeld (1901-1976), e os psicólogos Carl Iver Hovland (1912- 1961) e Kurt Zadek Lewin (1890-1947)". Posteriormente, Everett M. Roggers e Steven H. Chaffeem, publicam o livro The bennings of Communication Study in America: a personal memoir, onde Schramm é incluído como o grande fundador, como afirma Varão (2010, p. 77). 
do Ciespal, mais precisamente em duas edições ( $\mathrm{n}^{\circ} 49$ de 1994 e $\mathrm{n}^{\circ} 135$ de 2017) da Revista Chasqui. Para esta escolha, levou-se em consideração que as duas edições possuem o mesmo tema: Género y Comunicação, embora editadas em um espaço temporal de 23 anos. Após as etapas exploratória e de levantamento dos dados, muitas outras 'descobertas' foram feitas nos artigos disponibilizados nas duas edições, não somente em relação a produção comunicativa feminina, mas em especial na contabilização de outras pioneiras dos e nos estudos comunicativos na região.

Para atender o limite para esse texto, optamos por selecionar as editorias que tinham o como foco temático das edições a presença feminina (gênero), sistematizando, conhecendo e analisando a presença das pesquisadoras nos textos disponibilizados, trazendo reflexões iniciais sobre as demandas comunicativas registradas em suas incursões pela região. Definido o objetivo inicial, os resultados gerais estão divididos em duas partes: a primeira que traz um breve perfil do Ciespal e da Revista Chaqui e a segunda, os resultados alcançados e alguns indicativos na direção das especificidades das análises.

\section{Ciespal articulador do desenvolvimento comunicacional da América Latina}

É possível verificar a atuação do Ciespal sob diversos prismas e perspectivas. Quer sejam de compreensão da pluralidade, da interdisciplinaridade, da transdisciplinaridade, a epistemologia dos contextos singulares e, ao mesmo tempo, tão amplos das áreas dos interesses comunicativos latino-americanos. Mas não podemos reduzir toda essa experiência a uma herança unívoca, calcada apenas pela 'irreverência', como afirmam alguns teóricos, das pesquisas emergentes, inspiradas nas demandas sociais de uma época tão plural quanto conturbada. $\mathrm{O}$ olhar deve propiciar aos estudos sobre o tema a oportunidade de reflexões latino-americanas, mas formatadas nas diversidades técnicas e metodológicas, na exigência ética e na oportunidade de fundamen- 
tação teórica. Embora tenha recebido polemicamente adesão e repulsa da comunidade científica da época, o Centro possibilitou um espaço de meditação rumo às diversificadas demandas sociais que ultrapassavam as profissões e os saberes aparentemente legitimados.

O Ciespal foi fundado em 9 de outubro de 1959, na cidade de Quito, Equador. Tratou-se de uma iniciativa do governo equatoriano, da Unesco e da Organización de los Estados Americanos (OEA), para abrigar as necessidades de criar centros destinados a desenvolver atividades de ensino, privilegiando a formação de profissionais para atuar nas indústrias culturais da região, inicialmente na área do jornalismo. (Gobbi, 2002)

Para atender o crescente desenvolvimento das novas tecnologias de reprodução simbólica - offset, vídeo-tape, super-8, satélites - e aos novos enfoques comunicacionais, por volta dos anos de 1970, o nome da instituição sofre uma variação. A palavra "Periodismo" foi substituída por Comunicação. O Centro passa então a chamar-se Centro Internacional de Estudos Superiores de Comunicação para América Latina. A sigla Ciespal, no entanto, permaneceu inalterada.

Em seus primeiros anos de trabalho, dedicou-se principalmente à área do jornalismo ${ }^{9}$, posteriormente ampliando seu campo de atuação para a pesquisa, a documentação e a produção de materiais técnicos e didáticos.

A preparação de comunicadores sociais capazes de difundir a cultura, a ciência, a educação e a tecnologia, constava dentre os desafios do Centro. A formação oferecida incluía uma bibliografia de autores norte-americanos, em uma linha muito ligada ao jornalismo impresso, como afirma Prieto Castillo (200o). Buscava, do mesmo modo, investigar a realidade do continente latino-americano no que se referia à comunicação social e à participação efetiva dos meios nesse processo.

Ciespal permitía un punto de encuentro donde no eran infrecuentes los debates en torno a la realidad latinoamericana. De modo que en un contexto de enseñanza centrado en una cierta ingenuidad y en un énfasis en la formación orientada hacia la cultura y la profundización en algunos

9 A palavra comunicador não era utilizada por essa época (Prieto Castillo, 2000, p. 120). 
elementos del trabajo periodístico entraban también el intercambio de ideas y de experiencias (Prieto Castillo, 2000, p. 121).

Embora tenha exercido um papel muito importante na consolidação do campo da comunicação na região e propiciado um grande impulso ao desenvolvimento comunicacional Latino-Americano, as preocupações do Centro traziam nitidamente as próprias inquietações da Unesco, calcadas pela "paternização de um profissionalismo despreparado ou disfuncional para a Nova Ordem Política das áreas de influência no confronto Norte-Sul". O que não se imaginou foi que a incompreensão, motivada por identidades conflitivas com esse programa, pudesse colocar em xeque as reais intenções da Unesco e do próprio Ciespal. (Medina, 2000, p. 14,1)

Por outro lado, a variedade de sua produção, os ecos positivos encontrados em muitos pesquisadores de diversos países da região, que conclamavam por uma nova orientação de suas pesquisas, além de uma compreensão dos rumos da informação, reforçaram a atuação do Centro. Neste cenário ‘tão propicio e acolhedor', respaldado pela criação da ONU, em 1948; da Unesco, em 1949 e do Ciespal, em 1959; o mote da pesquisa em nosso continente passa a estar no contexto do estudo sobre a informação no sentido de estabelecer a paz e a integração, por meio da educação, da ciência e da cultura. (Gobbi, 2002)

Para dar conta dessa reivindicação, o Ciespal desenvolveu diversos encontros, publicações, cursos e seminários. Andrea Coronel Alvarez e Edith Vasquez Loyola, sob a orientação do professor Joaquin Moreno, em estudo realizado no mês de abril de 2000, na Universidad del Azuay, Facultad de Filosofia, Letras y Ciencias de la Educación, Escuela de Comunicación Social, Cuenca, Equador, classificaram a produção do Ciespal em dez tipos de coleções: Monografias Ciespal, materiais de trabalho, Cuadernos Chasqui, materiais didáticos, meios de Comunicação, Encuentros, Revista Chasqui, documentos e outros tipos de publicações. 
Em busca do fortalecimento acadêmico e do permanente intercâmbio profissional foi criada, em 1970, a Associação Nacional de Ex-bolsistas, que posteriormente originou a Federación Latinoamericana de Ex-becarios de Ciespal, com sede na cidade de Quito. A proposta da Federação era também a de oferece a prestação de serviço para o desenvolvimento da comunicação, realização de pesquisas científicas sobre os meios, colaboração para a formação e capacitação dos comunicadores latino-americanos e a manutenção de uma permanente vinculação com o Ciespal de forma a colaborar com os objetivos do Centro. (Gobbi, 2002)

O Ciespal organizou diversos cursos de formação profissional, dos quais participaram professores, estudantes e jornalistas de diversos países latino-americanos. As experiências trocadas durante os encontros possibilitam o conhecimento do gap existente entre as escolas de jornalismo, os profissionais e os meios de comunicação. Neste sentido, o Ciespal começou a formar profissionais "polivalentes capazes de atuar em todos os meios de comunicação coletiva (rádio, televisão, imprensa, cinema)" (Meditsch, 2000, p. 131), na pesquisa científica e na atuação em relações públicas e publicidade etc. Um dos pontos de consenso era de que as escolas não atendiam às necessidades do mercado comunicacional e que os cursos não dispunham de equipamentos necessários para propiciar aos estudantes a experiência prática. Por outro lado, os professores não tinham experiência e faltava bibliografia básica ao apoio dessas cátedras. Assim, o "Ciespal en 1960, fue la entidad que prácticamente comenzó en América Latina a promover la importancia y trascendencia de la enseñanza y práctica de la investigación al margen de expresiones verbalistas". (Galarza, 2000, p. 38).

Atualmente, na segunda década do século XXI, é possível afirmar que o Ciespal possui um grande acervo documental ${ }^{10}$. São livros,

10 De acordo com a professora Cremilda Medina (2000), o Ciespal publicava desde sua fundação uma série de documentos, entre eles, cadernos assinados por autores funcionalistas como Wilbur Schramm e Jacques Kayser. Esta bibliografia iniciava os bolsistas à pesquisa e às metodologias difundidas nos cursos. 
revistas, documentos, cadernos de pesquisa, compêndios, anuários, vídeos, textos, programas, resultados de pesquisa etc., que vem sendo acumulado desde a segunda metade do século passado e se constitui como um espaço aberto para a pesquisa. Do mesmo modo, tem sido um local de referência e acolhimento de investigações para pesquisadores não só da América Latina, mas de países europeus e estadunidenses.

\section{Revista Chasqui e sua importância na divulgação científica na América Latina}

Editada e publicada pelo Ciespal, a Revista Chasqui é pioneira no que tange aos estudos em comunicação na América Latina. Lançada no ano de 1972, a publicação vem "participando activamente del debate científico y social sobre políticas y estructura de la comunicación, periodismo, comunicación popular, nuevas tecnologías, entre otras temáticas" (Ciespal, 2021).

Nestes quase 50 anos de contribuições, dois detalhes merecem destaque. Resultado das crises instaladas em toda a região, a Revista deixou de ser editada no final de 1979, retornando em 1981, sendo esta a única interrupção. E no ano de 2015 ocorreu uma mudança editorial, com a ampliação dos espaços de diálogo e trazendo a "expectativa de establecer un campo fértil en favor de una Comunicación comprometida, crítica y latinoamericana”. (Ciespal, 2021)

A título de curiosidade o nome Chasqui é proveniente da "figura histórica del portador de noticias en el imperio Inca. El chasqui era el corredor encargado de llevar y traer la información, las encomiendas y, sobre todo, el portador del saber ancestral". (Ciespal, 2021)

Dividida por períodos, podemos dizer que de 1972 a 1978 foram 21 edições, que trazem um panorama geral das inquietudes temáticas da época, bem como as fontes e as metodologias que eram utilizadas. Em sua reinauguração em 1981, a Nova Ordem Internacional de Informação (NOII), resultante do Informe MacBride, direcionou os focos para uma 
investigação mais crítica sobre a democratização, as políticas de Comunicação e os direitos sociais, que estavam comprometidos por conta dos ‘estados de exceção' vividos em quase toda região.

A partir da década de 1990, afirma o site da Revista, "se consolida la presencia latinoamericana con autores que reivindican un fuerte compromiso social con la democracia y la comunicación, provenientes de Brasil, Argentina, México, Colombia, Uruguay, Paraguay, Bolivia, Perú, Ecuador, Venezuela, Cuba y otros", incluindo neste mote as tecnologias da informação e da comunicação, novas práticas profissionais, comunicação popular, história da Comunicação, entre outros temas, dentro de uma "perspectivas inter y trans disciplinarias, como respuesta epistémica a la colonialidad del saber, del poder y del ser". (Ciespal, 2021)

Indexada em importantes bases de dados, como a Web of Science Group, Redalyc, Emerging Sources Citation Index, Capes, Dialnet, Rede Iberoamericana (Redib), EBSCO Host, Diretory of Open Access Journals (Doaj), Latinex e Google Académico, tem como editora Gissela Dávila Cobo (ano de 2021). Conta com um corpo editorial composto por pesquisadores de diversos países da América Latina, além de um conselho científico internacional.

Em 2021, com 145 edições, a publicação tem um formato atraente e é assinalada como uma das mais prestigiosas revistas da área. Avaliada por pares, tem uma política editorial clara e integra o seleto grupo de revistas avaliadas ${ }^{11}$ com Qualis A2, no Brasil. Todo o acervo das edições está disponível no site do Ciespal para consulta aberta e gratuita.

Desenhado esse breve panorama é importante assinalar que a seguir estão alguns pontos de escolhas metodológicas e as análises iniciais resultantes dessa incursão pela Revista. Não foi possível, no espaço do artigo, trazer todas as apreciações realizadas. Deste modo, mais uma vez, a seleção objetivou trazer pontos de interseção para a compreensão das concepções sobre a produção feminina nos estudos co-

11 São procedimentos utilizados pela Coordenação de Aperfeiçoamento de Pessoal de Nível Superior (CAPES) para estratificação da qualidade da produção intelectual dos programas de pós-graduação no Brasil. Classifica em estratos que variam entre A1, A2, A3, A4, B1, B2, B3, B4 e C, sendo o A o mais elevado. Outras informações podem ser obtidas na página web da entidade. 
municativos latino-americanos, conforme mencionado anteriormente, possibilitando o desenho de um cenário que ainda carece de pesquisas mais ampliadas e aprofundadas.

\section{A presença da mulher no contexto dos estudos em comunicação na América Latina}

Retomando a proposta de trazer os resultados iniciais ${ }^{12}$ de uma investigação mais ampla, que objetiva (re)desenhar o mapa das contribuições comunicativas pioneiras ao PCLA também na perspectiva da produção feminina, parte de pesquisas que venho realizando desde o meu doutoramento, no ano de 1999. As incursões aos estudos comunicativos, por essa época, já possibilitavam verificar que a presença feminina era notada de forma bastante tímida ou então, muitas vezes, estavam reforçadas e reproduzidas em versões estereotipadas sobre o papel social da mulher. Essas aproximações iniciais trouxeram, para mim, perspectivas de estudos futuros.

As primeiras buscas por um repertório teórico que pudesse assinalar os motivos dessa ainda aparente invisibilidade feminina na área apresentaram poucas respostas. Fazendo uma apropriação das reflexões de Rosaldo e Lamphere (1979), existiam poucos instrumentos teóricos para a compreensão ou descrição da comunicação sob o ponto de vista feminino. Tal fato assinalava para a ocorrência de que se poderia ter desenhado um mapa teórico-conceitual distorcido dos estudos na área da comunicação. O desafio de aprofundamento dos estudos nessa área se constituiu, então, em diversas questões que precisavam e ainda precisam ser respondidas.

Desta forma, focalizando a mulher e os "fatos até então tradicionalmente ignorados ou considerados naturais" no campo ainda jovem da comunicação acredito, sem nenhuma presunção pessoal, na possibilidade de reavaliar antigas teorias e iniciar o "caminho para

12 Apoio da Fapesp. Processo 2019/26715-2. 
reflexões futuras" no sentido de (re)desenhar esse mapa teórico-conceitual, agora com a presença das mulheres. E assim como Rosaldo e Lamphere (1979), o desafio-problema se e amplia e passa a se constituir em como iniciar essa jornada.

É importante assinalar que o resultado de algumas pesquisas realizadas, bem como o exame em livros e textos (disponíveis) que tratam sobre o tema da comunicação no espaço latino-americano, suas teorias e metodologias, tanto nas autorias como no referencial bibliográfico citado há um ‘ocultamento' dos nomes de pesquisadoras. Isso nos leva a questão trazida para essa reflexão em observar as contribuições, ainda iniciais do ponto de vista do material apresentado, sobre a concepção do pioneirismo feminino na área da comunicação, na América Latina.

Assim, amparada pela justificativa de que a busca dessas produções 'silenciadas' na historiografia "coincide com a busca de uma História das Mulheres, gênero esquecido durante longo período em que a história (...)" do PCLA "foi construída ou deformada de acordo com as forças políticas envolvidas" (Nascimento, 2015, p. 286), que venho empreendo meus estudos.

É de ater-se que o desafio na busca por respostas para a não presença das mulheres nos estudos comunicativos em várias regiões se expandiu de maneira cientificamente estimulante. Quer a partir das pesquisas sobre os medias (impresso, cinema, rádio ou televisão) ou mesmo por intermédio das diversas escolas de pensamento, como Frankfurt, Francesa, Birmingham etc., ou ainda em teorias e temas que norteiam os campos investigativos comunicativos (jornalismo, publicidade, relações públicas, rádio e televisão etc.), tais como agendamento, valores notícia, cultura, opinião pública, hipodérmica, espelho, empírico-experimental etc. Esta invisibilidade da produção feminina se torna mais perceptível se considerados a apresentação de outros ambientes midiáticos, com os suportes da web (blog, sites, redes sociais, por exemplo). Assim, pode-se afiançar que o 'ocultamento' extrapola para o espaço cognitivo, onde na construção crítica da realidade comunicativa, quem busca pela produção das mulheres 
encontra a ausência ou a deformação de conceitos e concepções, gerando muitas vezes, respostas equivocadas em sua interpretação, especialmente quando se considera que a história é uma forma de ver a sociedade. (Nascimento, 2015)

Uma visível complexidade está contida em dois pontos: o primeiro é a sistematização desta produção para, em seguida, realizar a "revisão do cânone e da literatura de autoria feminina: não só revisão, mas pesquisa e estudo sobre obras de autoria feminina nunca antes estudada" (Nascimento, 2015, p. 297).

Considerando o fato da escassez de material, o caminho inicial foi o de ampliar o leque para artigos escritos pelas mulheres e para outros que tenham elas como protagonista ou foco de análises a partir de sua produção comunicacional. Há, desde então, várias reflexões sendo construídas e que como bem assinalam Rosaldo e Lamphere (1979, p.14) evidenciam que "nossas próprias concepções sobre a mulher tornamse cada vez mais sofisticadas".

Desenhada a justificativa, a escolha para essa reflexão foi a de trazer os artigos disponibilizados na Revista Chasqui motivada, especialmente, pelos argumentos anteriormente descritos. E para atender o espaço do texto, a alternativa de duas edições, dentre as quatro que trazem a mulher como tema central da publicação, foi a escolha.

Esta pesquisa suplanta a crítica essencialista da dualidade (mulher/homem) e se pauta no gênero enquanto categoria para análise histórica, rejeitando o caráter fixo e permanente da oposição binária presentes na construção hierárquica da relação entre masculino e feminino. Assim, "em lugar de procurar as origens únicas, temos que conceber processos tão ligados entre si que não poderiam ser separados". E como reforça Scott (1995, p. 20), "Temos que nos perguntar mais frequentemente como as coisas acontecem para descobrir porque elas acontecem". O estudo também se pauta pela formulação de Michelle Rosaldo (1979, p. 33), quando afirma que "temos que procurar não uma causalidade geral e universal, mas uma explicação significativa (...)" do motivo, entendendo que o lugar da mulher nos 
estudos comunicativos não é "diretamente o produto do que ela faz, mas o sentido que as suas atividades adquirem através da interação social concreta", presentes na história da comunicação na América Latina.

Formulada as justificativas metodológicas, a adoção de um único método é insuficiente para o êxito pretendido, considerando a diversidade e amplitude temporal do material selecionado. Por esta razão, optou-se por trabalhar com um conjunto metodológico no intuito de contemplar os objetivos propostos. Neste complexo procedimental, a estratégia inicial foi realizada no espaço web do Ciespal, utilizando a pesquisa bibliográfica "como um procedimento metodológico importante na produção do conhecimento científico capaz de gerar, especialmente em temas pouco explorados, a postulação de hipóteses ou interpretações que servirão de ponto de partida para outras pesquisas" (Lima \& Mioto, 2007, p. 44). Com esse procedimento foi possível resgatar e sistematizar a produção das mulheres contida na Revista Chasqui, onde os estudos pioneiros foram disseminados e orientaram e ainda orientam a formação de um pensamento comunicacional, na região. $\mathrm{E}$ a partir do escopo mais amplo, selecionar parte das edições que foram analisadas para esse texto.

Conforme exposto, a escolha dos materiais para análise se deu a partir da categoria 'gênero', que como afirma Scott (1995, p. 76) é "um conceito associado ao estudo de coisas relativas às mulheres. 'Gênero’ é um novo tema, um novo domínio da pesquisa histórica, mas não tem poder analítico suficiente para questionar (e mudar) os paradigmas históricos existentes", justificando assim a inclusão de outras duas categorias de análise. A primeira com referência a comunicação e a outra relacionada ao espaço latino-americano, onde tenho empreendo minhas investigações. A partir da concepção de gênero escolhida, considera-se que, 
[...] o gênero é uma forma primária de dar significado às relações de poder. Seria melhor dizer: o gênero é um campo primário no interior do qual, ou por meio do qual, o poder é articulado. $O$ gênero não é o único campo, mas ele parece ter sido uma forma persistente e recorrente de possibilitar a significação do poder no ocidente, nas tradições judaico-cristãs e islâmicas. (Scott, 1995, p. 88)

Deste modo, como reforça a pesquisadora, se estabelecidos como "um conjunto objetivo de referências, os conceitos de gênero estruturam a percepção e a organização concreta e simbólica de toda a vida social", fornecendo então o instrumental necessário para o entendimento dos atrelamentos e vinculações "entre várias formas de conexão". Assim,

[...] quando os/as historiadores/as buscam encontrar as maneiras pelas quais o conceito de gênero legitima e constrói as relações sociais, eles/elas começam a compreender a natureza recíproca do gênero e da sociedade e as formas particulares e contextualmente específicas pelas quais a política constrói o gênero e o gênero constrói a política. (Scott, 1995, p. 88)

A historiografia é uma "construção narrativa dos resultados da pesquisa histórica, realizada a partir do controle metódico de investigação empírica e de crítica documental” Cordeiro (2019, p. 10). Nessa perspectiva, é possível afiançar que "é ela que dá forma e feitio histórico aos elementos empíricos (objetivos) da pesquisa, inserindo-os na vida prática, atribuindo-lhes sentidos e significados", como avaliza Cordeiro (2019, p. 10), evidenciando o conceito de uma historiografia social.

Também é importante ponderar que para a realização de um trabalho histórico é necessário o resgate sobre aquilo que se deseja empreender, não sendo possível definir o marco inicial como ponto zero, "decretando a 'morte cívica' de todas as pessoas que se voltaram a este ou aquele objeto" (Cordeiro, 2019, p. 11). Deste modo, o "encontro com a historicidade", como relata Cordeiro (2019, p. 12), 
[...] é significativo de um descompasso entre a experiência vivida como tal e o relato possível que sobre ela se constrói. É também um descentramento de si, uma viagem para fora de si mesmo em direção a novas fronteiras a serem delineadas, novas experiências a serem incorporadas e a posterior volta, que já não será a volta ao lugar original de partida. Tal historicidade parece impregnar o próprio trabalho da escrita da história, organizando a narrativa dos eventos e propiciando ao leitor o movimento para fora do seu tempo e de seu lugar e dessa forma a incorporação de novas experiências, alargando seu horizonte de possibilidades (Guimarães, 2006, p. 47). Tendo em vista essa compreensão de historicidade, e admitindo seu caráter constitutivo da própria historiografia (um produto da história), recomenda-se, para qualquer trabalho que se pretenda de história da historiografia, atentar-se para essa questão, de forma a apreender as obras historiográficas inseridas no seu tempo, no seu contexto histórico e na sua historicidade.

O entrelaçamento entre passado, presente e futuro fornece "ferramentas para compreender a experiência” (Cordeiro, 2019, p. 11). Para Koselleck (2006), através da dimensão do presente e de questionamentos atuais, é possível não somente reconstruir o passado, mas (res)significá-lo como futuro. Destarte, nos trabalhos historiográficos se faz fundamental as busca pelos contextos de produção daquilo que será analisado, possibilitando a ordenação temporal e tornando "significativo um conjunto disperso de experiências e vivências (...), sem lançar mão de um horizonte de expectativas” (Cordeiro, 2019, p. 13).

Do mesmo modo, espera-se, com o desenvolvimento de todas as etapas propostas na pesquisa mais ampla que está sendo empreendida, conforme citado anteriormente, alcançar algumas respostas às indagações existentes sobre a presença da mulher nos estudos pioneiro da América Latina para, a partir disso, propor reflexões sobre o (re)desenho do quadro de referência dos estudos em comunicação na região.

Finalmente, as incursões propostas para esse texto, contribuíram para o desafio do desenvolvimento do quadro de referências comunica- 
cionais no cenário da América Latina, incluindo produções que ficaram esquecidas, especialmente aquelas com autoria feminina. Acredito, assim, que considerando, igualmente, os esforços que vem sendo empreendidos em outros levantamentos que estão sendo realizados, será possível propor mudanças para o ensino das teorias da comunicação no panorama contemporâneo.

\section{Breves contribuições sobre a produção feminina na área}

Na literatura da área, de fato, parece evidenciar-se uma condição de exclusão de referenciais dos estudos realizados por mulheres, embora esforços importantes tenham sido realizados por pesquisadoras como Lillian Ross, "pioneira do novo jornalismo (ou jornalismo literário)", que reinventa os limites da reportagem nas páginas da The New Yorker; Gertrude Robinson, Canadá, que "não hesitou em proclamar como território monopolizado pelo gênero masculino", argumentando que as contribuições femininas "vem sendo minimizadas, ignoradas ou escamoteadas" (1998) do rol comunicativo. Do mesmo modo, Aimee-Marie Dorsten (2012) contesta a 'dominação masculina' e apresenta as contribuições de Hortense Powdermaker, Mae Huetting e Helen MagGill no desenvolvimento dos estudos em comunicação, em contraposição a Harold Lasswell, Dallas Smythe e Paul Lazarsfeld. A 'Espiral do Silêncio', da pesquisadora Elizabeth Noelle-Neumann, que protagoniza os primeiros estudos sobre a Teoria, ainda nos anos de 1960, sendo a única teoria "que tem assinatura feminina no universo cognitivo monopolizado pelo gênero masculino", bastando uma consulta aos manuais de Teorias da Comunicação vigentes em diversos países para comprovar a afirmação. Do mesmo modo, protagonistas como Irena Tetelowska ${ }^{13}$, polonesa, no âmbito da Unesco e Anne Marie Thibault-Laulan, francesa, na International Association for Media and Communication Studies

13 "Sua trajetória acadêmica através da edição especial em inglês da revista também por ela criada Zeszyty Prasoznawcze (Cracovia,1971). Primeira mulher a galgar posição de realce nos quadros dirigentes da referida associação mundial, ela sem dúvida inspirou a luta tenaz que foi ali travada por Gertrude Robinson e suas companheiras de geração". (Melo, 2012, informação oral). 
(IAMCR) "que teve um papel relevante na cooperação da França com a América Latina", além de organizar a antologia 'Imagem e Comunicação', publicada em 1976, pela Melhoramentos, no Brasil. Também estão os trabalhos de Brenda Dervin (USA), entre outras. (Melo, 2012, informação oral).

Na região latino-americana, do mesmo modo, há trabalhos historicamente significativos e igualmente desaparecidos. Podem ser citadas as contribuições de pesquisadoras como: Michèlle Mattelart (Chile), que 1968 publica La mujer chilena en una nueva sociedad, entre muitos outros (no seu retorno a França), com destaque as suas crítica feminista a indústria cultural; Mabel Piccini (Chile), na década de 1970 publica Los medios de comunicación de masas. La ideología de la prensa liberal e entre l968 y 1973 investiga sobre política y medios de comunicación, além de uma densa produção no México, Espanha, França, Argentina, entre outros trabalhos produzidos durante e após seu exílio em 1976; Matilde Perez Palacios (Peru) que exerceu a presidência da Federação Católica Latino-Americana de Escolas de Jornalismo (Periodistas Católicos, 1968), tendo publicado diversas pesquisas relacionada aos estudos de comunicação religiosa. Marta Colomina de Rivera (Venezuela), que estudou a função das telenovelas na sociedade latino-americana (1968), em cujos resultados estão em seu livro Huésped Alienante. Fátima Fernandez (México), fundadora da Asociación Mexicana de Investigadores de la Comunicación (AMIC), sendo uma de suas publicações o livro Los medios de difusión masiva en México de 1982. Patrícia Anzola (Colômbia) "desencadeou uma ofensiva para resgatar a memória da pesquisa em comunicação num bloco formado pela Argentina, Brasil, Chile, Colômbia e Peru" e também, integrou a diretoria da Alaic. (Melo, 2012, informação oral).

Estão, ainda, neste rol pesquisadoras como as brasileiras: Zita de Andrade Lima que realizou e apresentou durante o I Curso realizado pelo Icinform a Bibliografia Brasileira de Jornalismo, ainda na década de 1960, publicou Princípios e Técnicas de Rádio Jornalismo, em 1970 a partir de sua dissertação de mestrado desenvolvida na Universidade de Brasília, 1967 e O Rádio no Brasil, apresentado no I Congresso Nacio- 
nal de Comunicação, realizado no Rio de Janeiro, em 1971, entre muitos outros. E Margarida Kunsch (Brasil), que tem se dedicado aos estudos sobre comunicação na América Latina, além de ter dirigido a Alaic e de edita a 'Revista Latino-Americana de Ciências da Comunicação'. Somam-se a lista, Adisia Sá, primeira mulher a militar profissionalmente no jornalismo cearense, tomando a frente do movimento para criar o Curso de Jornalismo da Universidade Federal do Ceará. Neste tema, cabe ressaltar a importante contribuição de Lúcia Castelón, que revitalizou o ensino de comunicação no Chile.

Ainda juntam-se a este contingente: Silvia Álvarez (Puerto Rico); Cristina Baccin; Mabel Grillo e Maria Cristina Mata (Argentina); Ana Maria Cano; Maria Teresa Quiroz e Carla Colona Guadalupe (Perú); Diana Kiss e Denise Shomalí (Chile); Rossana Martel (El Salvador); Luz Neira Parra e Migdalia Pineda (Venezuela); Dania Pilz (Paraguai); Rossana Reguillo (México); Carmen Rico e Ana Cecilia Solari (Uruguai); Ingrid Steinbach (Bolívia); Yanet Toirac (Cuba), entre outras.

Lançado em 2020, o livro editado por Clemencia Rodrígues, Claudia Magallanes Blanco, Amparo Marroquím Parducci e Omar Rincón, produzido Centro de Competencia en Comunicación para América Latina e pela Fundación Driedrich Ebert (FES), traz outras produções comunicativas desenvolvidas por mulheres, referendando ainda mais a assertiva da produção feminina na área. São 20 mulheres que refletem criticamente sobre a comunicação feminista, a indústria cultural, a tecnopolítica, a epistemologias, o desenvolvimento comunicativo, a comunicação popular, entre outras temáticas, passando pelas mídias e pelos movimento sociais, políticos, econômicos e de minorias da região.

Fazendo uma breve reflexão dos dados apresentados, pode-se observar que não são: a região de origem do estudo e/ou a 'diferença de língua' as justificativas para a supressão dos estudos das mulheres estarem presentes nos referenciais da área, uma vez que no cenário Latino-Americano o silenciamento, também, existe de fato quando 
consideramos a produção inicialmente elencada e que não aparecem como referência.

\section{Contribuições da Revista Chasqui ao tema}

Fazendo uma incursão inicial pelas 145 edições disponibilizas no site do Ciespal encontramos 4 publicações que trazem as questões de gênero ou a temática mulher figurando como ponto central da edição. São elas: Ed. 4 (1982) - Tema: La mujer en los medios de información y comunicación; Ed. 49 (1994), Tema: Género y Comunicación; Ed. 57 (1997), Tema: Sociedade, mujer y comunicación. Erotismo, pornografía y medios e a Ed. 135 (2017), Tema: Género y Comunicación. Embora o foco central assinalado para esse texto não seja especificamente sobre as discussões de gênero, mas refletindo sobre a presença feminina nos estudos comunicativos, a produção das mulheres estava mais amplamente representada nas edições 49 (1994) e 135 (2017) e na temática escolhida 'Género y Comunicación'. Conforme anteriormente mencionado, e escolha foi também motivada pelo fato das duas publicações terem o mesmo tema e serem editadas em espaços temporais distantes, podendo igualmente contribuir para o conhecimento sobre a mudança, a evolução e os olhares mais atuais da presença feminina nos estudos da área.

Assim, observando as duas edições, algumas peculiaridades merecem ser destacadas, em especial na perspectiva dos conteúdos avaliados. A edição no 49 trouxe 6 divisões, que são: Carta del Editor, Del libro a la pantalla; Dias de Radio; Entrevistas; Comunicación y Gênero e Debate, que estão mais próximas de uma separação temática tratada pela edição do que a uma perspectiva de editorias. O volume 135, com outro desenho gráfico, define as partes: Editorial, Tribuna, Monográficos. Género y Comunicación; Ensayo; Informe; Reseñas. Para atender a perspectiva do texto a divisão (editoria) Género e Comunicación foi a selecionada para análise, nas duas edições. 
Já na abertura da edição 49, encontramos o reforço para a escolha das edições. O texto afirma que "Comunicación y Género, acopia trabajos que vinculan a la mujer y la comunicación y sus esfuerzos por no ser consideradas inferiores". É complementado no sumário, onde afirma que "En los últimos años se comenzó a dar más importancia a la relación entre género y comunicación, sin embargo, todavía queda un largo camino por recorrer" (Chasqui (49), 1994), robustece as assertivas iniciais da reflexão proposta e estimula a continuidade dos estudos que ora estamos empreendendo. Não diferente foi a chamada da edição 135 (2017) que nos conclama a refletir sobre,

\begin{abstract}
¿Podremos preguntarnos qué vinculación tiene la exclusión sistemática de las mujeres, la violación, la violencia con estas formas de depredación económica y emocional en la que están inmersas todas las sociedades, con la extrema crisis emocional y económica del capitalismo? El desafío de este número de la Revista Chasqui es entramar al género y a los feminismos en los discursos cotidianos de todos los temas por los que transita nuestra existencia. Sacar al género del armario y ponerlo en cada una de las letras cotidianas es el propósito de un número que desea revitalizar argumentos que nos inviten a construir otros modos de estar juntas. (Chasqui, 2017)
\end{abstract}

Deste modo, a partir dos desafios nomeados é fundamental realizar o resgate histórico, não somente no sentido de delinear as discussões teóricas e ilustrar linhas de reflexão, mas também de produzir a integração de um interesse da mulher dentro das teorias comunicativas, amparado na produção acadêmica de cunho teórico-conceitual e na prática profissional. Entender como tudo isso começou, verificando que o conflito gerado pela invisibilidade feminina se faz presente na área, e que esse regate pode tornar significativo "um conjunto disperso de experiências e de vivências" (Cordeiro, 2019, p. 13), é o que nos estimula.

As duas edições somam 53 textos (considerando os editoriais), sendo que contribuições assinadas pelas mulheres estão presentes em 23 
artigos e em mais 5 desenvolvidos em parcerias entre homem e mulher. O conjunto analisado na editoria de gênero e comunicação é composto por 7 textos da edição 49 e 11 da edição 135. Nesta última, houve a inclusão de mais um artigo que está fora do dossiê na organização da revista, mas que tem como foco nos estudos de gênero e, portanto foi incluído, formando o total 19 materiais para exame. A contribuição feminina com base na editoria escolhida está representada em 10 artigos, escritos de forma individual ou em parcerias, somando as duas publicações. Porém, primando pela não dicotomia entre sexos, a análise ocorreu em todo o material selecionado (19 textos) das duas edições. No conjunto, o foco das reflexões traz acontecimentos vivenciados ou estudados na perspectiva da América Latina.

Há uma diferença significativa no formato das duas publicações. Na edição 49 a produção é mais autoral, realizada por comunicadoras sociais, sociólogas, ativistas midiáticos, coordenadoras de documentação, editoras e jornalistas, estando assim mais próximo do formato de artigos jornalísticos, enquanto na edição 135 todo o material tem o desenho de artigos científicos e são subscritos por profissionais que se assumem acadêmicas e acadêmicos. Assim, na edição de 1994 todos os artigos são assinados individualmente, enquanto em 2017 já é possível observar a produção conjunta, não somente entre pesquisadores de ambos os sexos, mas entre países, evidenciando a amplitude das reflexões para além das próprias localidades dos relatos.

O resultado, também, assinala não somente a mudança editorial da revista, mas fazendo uma análise breve do perfil da publicação na década anterior, é possível observar que a participação de profissionais atuantes na área ou mesmo militantes das causas sociais se fazia mais presente nas primeiras edições. Assim, os relatos disponibilizados na edição 49, em sua grande maioria, são resultados de conhecimentos práticos no campo profissional, que evidenciam, muitas vezes, o perfil do media, as dificuldades enfrentadas na carreira, experiências cotidianas da profissão e demandas da sociedade, decorrência do contato direto do profissional com a população. São exem- 
plos os textos: El ovido de la mujer sujeto, de Rosa Maria Alfaro, que traz um contraponto entre a pesquisa acadêmica e a luta das mulheres rurais; em Periodismo diferente, de Yoloxochitl Casas Cousal, que relata a exclusão feminina dos meios de comunicação no México ou ainda a entrevista de Lúcia Lemos no texto Mirta Rodriguez y "Bohemia”, que mostra o pioneirismo da entrevistada em sua luta para falar de gênero, machismo e feminismo em Cuba e os desafios para manter a Revista Bohemia circulando.

Na edição 135, as experiências estão presentes através do diálogo com o referencial teórico-metodológico, em análises das temáticas tratadas pelos veículos de comunicação e suas representações em períodos históricos, como apresentado nos textos sobre a ditadura stronista no Paraguai (1959), de Aníbal Orué Pozzo \& Florencia Falabella ou na discussão "Perversão e política no impeachment de Dilma Roussef", ex-presidenta do Brasil, de Muriel Emídio Pessoa do Amaral \& José Miguel Arias Neto, entre outros.

O material, igualmente, origina discussões acadêmicas sobre o enfrentamento da mulher aos temas da exclusão, da violência, da prostituição, da educação, da representação etc., sem perder de perspectiva o olhar crítico sobre a produção midiática disponibilizada nos diversos veículos de comunicação. Utilizam vasto referencial teórico-metodológico, contemplando diversas áreas do conhecimento, como: Comunicação, Sociologia, Política, Semiótica, Educação, Gênero, Antropologia, etc.

Desta forma, é possível assinalar que a primeira edição analisada, de 1994, tem como fonte os relatos das experiências sociais vivenciadas cotidianamente pelas comunicadoras sociais, bem como as lutas femininas por sobrevivência diante da imposição de modelos normativos de uma sociedade patriarcal. Já a edição de 2017 evidencia a agenda da mídia e da pesquisa acadêmica, trazendo o olhar crítico aos temas das minorias, presentes nas representações midiáticas e assinalados nas agendas econômica, política, social e da mídia, evidenciando as formas de representação patriarcal que reproduz e reforça uma visão estereotipada sobre o papel da mulher na sociedade. 
O resultado conjunto permite refletir que a dualidade entre sexos e o resultado disso "forma parte de una metafísica sublimada como sentido común por las representaciones de los medios”. Avigora Sierra Caballero (2017, p. 10), que a pesquisa acadêmica "apenas ha sido consciente - a nivel micro, e incluso menos desde el punto de vista de las agendas, políticas y representación patriarcal de la mujer por el propio sistema de ciencia y tecnología”, reforçando a desigualdade, os estereótipos e a ideologia sexista em sistemas como a divisão do trabalho, as garantias individuais, a segurança e o direito humano. O material analisado, por outro lado, vivifica uma mudança significa que vem ocorrendo, trazendo novos marcadores sociais e orientações de atitudes presentes nos valores compartilhados através das novas redes de interação social, propiciando uma nova interpretação dos acontecimentos e dos fenômenos da vida social.

Ainda, é possível observar que na editoria estudada das duas publicações, o Brasil contribuiu com 4 textos; Argentina e Equador, com 3; México e Espanha com 2, sendo um deles em parceria com pesquisador de outra região. Colômbia, Costa Rica, Cuba, Paraguai, Peru e Uruguai com um texto cada.

O conjunto das duas edições permitiu constatar como paulatinamente o cenário comunicacional, quer através das práticas profissionais ou das produções acadêmicas, vêm ampliando presença da mulher como sujeito ativa do e no processo comunicativo, considerando as autorias do texto ou mesmo o foco das reflexões trazidas.

\section{Retomando a pesquisa proposta - considerações}

Disponibilizado esse breve panorama é possível afiançar que existe, de fato, uma produção comunicativa de pesquisadoras e que estão presentes nas edições estudadas. A ideia inicial de considerar nas análises o referencial citado nos artigos, em especial da edição de 2017 não foi possível. A normatização da APA, utilizada como padrão 
pela Revista, privilegia o sobrenome, abreviando o nome, tornando a identificação bastante complexa. Assim, optamos pela leitura de todo o material buscando as pistas da presença das mulheres no referencial bibliográfico utilizado.

Retirando algumas autocitações, puderam ser identificadas diversas contribuições. Entre os "achados” é possível elencar os nomes que são citados nas edições, quer como referencial teórico-metodológico ou ainda como "sujeito" da reflexão. Dentre as pesquisadoras encontradas podemos citar: Maria Cristina Mata, Rosa María Alfaro, Mirta Rodríguez, Yoloxóchitl Casas Chousal, Marcela Lagarde, Rosa Nidia Buenfil Burgos, entre outras.

A proposta inicial de "mães fundadoras" precisa ser aprofundada e esse material oferece pistas importantes para análises posteriores.

Finalizando, há uma ainda aparente universalidade do domínio masculino nesse campo de estudos e de pesquisa. Como afirmam Rosaldo e Lamphere (1979, p. 27), os resultados oferecem a oportunidade de uma "análise crítica da universalidade da subordinação feminina, propõem que a desigualdade não é uma condição necessária das sociedades, mas um produto cultural passível de mudança”. É isso se constitui em estímulo para a continuidade dos nossos estudos.

\section{Referências}

Cano, Gabriela \& Barrancos, Dora (2006). “Introducción”. In Guadalupe Gómez-Ferrer Morant. Historia de las Mujeres en España Y América Latina (III): Del Siglo XIX A Los Umbrales Del XX. Madrid: Cátedra.

Capes. Coordenação de Aperfeiçoamento de Pessoal de Nível Superior (2021). Recuperado: https://sucupira.capes.gov.br/sucupira/public/consultas/coleta/ veiculoPublicacaoQualis/listaConsultaGeralPeriodicos.jsf

Ciespal. Centro Internacional de Estudios Superiores de Comunicación para America Latina. (2021). Apresentação. Revista Chasqui. Equador. Autor. Recuperado de http://www.ciespal.org 
Chasqui (1994). Género y Comunicacón. Edición número 49. Revista do Centro Internacional de Estudios Superiores de Comunicación para America Latina. Recuperado de http://www.ciespal.org

Chasqui (2017). Género y Comunicacón. Edición número 135. Revista do Centro Internacional de Estudios Superiores de Comunicación para America Latina. Recuperado de http://www.ciespal.org

Cordeiro, Cecília Siqueira (2019). Historiografia e história da historiografia: alguns apontamentos. In XXVIII Simpósio Nacional de História. Lugares dos historiadores velhos e novos desafios. Florianópolis-SC, jul 2015. Recuperado de http://www.snh2015.anpuh.org/resources/anais/39/1428357432_ARQUIVO_ArtigoSNH2O15Historiografia.pdf

Corner, John. (2019). "Origins and transformations: histories of communication study”. In Media, Culture \& Society.

Coronel Alvarez, Andrea e Vasquez Loyola, Edith (2000). Compendio de resumenes bibliograficos de obras publicadas por Ciespal: de 1959 a 1999. Trabalho de conclusão de curso da Universidad del Azuay, Facultad de Filosofia, Letras y Ciencias de la Educación, Escuela de Comunicacion Social, sob a orientação do profesor Lcdo. Joaquin Moreno. Cuenca: Ecuador, abril.

Fuentes Navarro, Raul (2019). "Pesquisa e metapesquisa sobre comunicação na América Latina”. In Revista Matrizes, V.13 - № 1 jan./abr. 2019. São Paulo: USP, 2019.

Galarza, Gonzalo Córdova (2000). "La investigación de la comunicación colectiva". In Bernedo, Franz Portugal Bernedo. La investigación en comunicación en América Latina 1970-2000. (p. 38). Lima: Apfacom.

Gobbi, Maria Cristina (2002). Escola Latino-Americana de Comunicação: o legado dos pioneiros. Tese de doutoramento defendida no Programa de Pós-Graduação em Comunicação Social, da Universidade Metodista de São Paulo, sob a Orientação do Professor José Marques de Melo.

Guimarães, Manoel Luiz Salgado (2006). "Escrever a história, domesticar o passado". In Antonio Herculano Lopes [et. al.] (orgs.). História e Linguagens. Texto, imagem, oralidade e representações. Rio de Janeiro: 7Letras.

Ilce. Instituto Latinoamericano de la Comunicación Educativa (2021). "Presentación”. México. Recuperado: https:/web.archive.org/web/20090925010728/ http:/www.ilce.edu.mx/v5/index.php?option=com_content\&task=view\&i$\mathrm{d}=584$ \&Itemid $=652$.

Koselleck, Reinhart (2006). Futuro passado: contribuição à semântica dos tempos históricos. Pontifícia Universidade Católica do Rio de Janeiro. 
Léon Duarte, Gustavo (2010a). Sobre la institucionalización de la comunicación en América Latina. México: Pearson-Pretice Hall.

Léon Duarte, Gustavo (2010b). "El papel de la Ciespal en el proceso de institucionalización de los estudios de Comunicación en América Latina”. In Revista MHCJ - Miguel Hernández Communication Journal. Ano 3, Artículo nº 13-38. México, pp. 217-261.

Lima, Telma Cristiane Sasso de \& Mioto, Regina Célia Tamaso (2007). "Procedimentos metodológicos na construção do conhecimento científico: a pesquisa bibliográfica”. In: Rev. Katál. Florianópolis v. 10 n. esp. pp. 37-45.

Meditsch, Eduardo (2000). "Ciespal trouxe progresso... e o problema quase insolúvel do comunicólogo”. In José Marques de Melo \& Maria Cristina Gobbi (orgs). Gênese do pensamento comunicacional latino-americano: o protagonismo das instituições pioneiras - Ciespal, Icinform, Ininco. (pp. 129-138). São Bernardo do Campo: Umesp.

Medina, Cremilda (2000). "O Ciespal e o resgate das vozes do hemisfério sol”. In José Marques de Melo \& Maria Cristina Gobbi (orgs). Gênese do pensamento comunicacional latino-americano: o protagonismo das instituições pioneiras - Ciespal, Icinform, Ininco. (pp. 139-148). São Bernardo do Campo: Umesp.

Nascimento, Michelle Vasconcelos Oliveira do (2015). "Sobre a história da literatura e o silenciamento feminino: questões de crítica literária e de gênero". In Historice. Rio Grande, v. 6 (1): (pp. 283-301). Recuperado: https://periodicos. furg.br/hist/article/view/54,18

Melo, José Marques de (2012). Aula Magna. Proferida em Bauru (SP), a convite da Faculdade de Arquitetura, Artes e Comunicação (FAAC), da Universidade Estadual Paulista Júlio de Mesquita Filho (UNESP), por iniciativa dos Programas de Pós-Graduação em Comunicação e TV Digital.

Melo, José Marques de (2001). Conhecer-produzir-transformar: paradigmas da Escola Latino-Americana de Comunicação. In Comunicação \& Sociedade, $\mathrm{n}^{\circ} 36$, ano $23,2^{\circ}$ semestre. São Paulo: Umesp.

Prieto Castillo, Daniel (2000). "La experiência de Ciespal en la década del 8o". In José Marques de Melo \& Maria Cristina Gobbi (orgs). Gênese do pensamento comunicacional latino-americano: o protagonismo das instituições pioneiras - Ciespal, Icinform, Ininco. (pp. 119-128). São Bernardo do Campo: Umesp.

Resende, Viviane de Melo (2021). O espaço paradoxal da academia latino-americana: pensamento aprisionado, pensamento que aprisiona? In Revista Wirapuru (2), ano 1, pp. 74-80. doi: 10.5281/zenodo.4641123.

Rosaldo, Milchelle Zimbalist \& Lamphere, Louíse (1973). A mulher, a cultura e a sociedade. Rio de Janeiro: Paz e Terra. 
Scott, Joan (1995). "Gênero: uma categoria útil de análise histórica". Texto original: Gender: a useful category of historical analyses. Gender and the politics of history. New York, Columbia University Press. 1989. In Educação \& Realidade, 20(2): 71-99, jul./dez.

Sierra Caballero, Francisco (2017). Comunicación y género. Agendas y cultura de investigación. Revista Chasqui (135). Equador: Ciespal.

Varão, Rafiza (2010). "Notas sobre o mito dos quatro fundadores do campo comunicacional: coisas que ninguém nunca viu antes e pensamentos que ninguém teve". In Revista Líbero, v. 13, n. 25. São Paulo, jun. de 2010, pp. 77-86. 